\title{
EL MAGREB Y ESPAÑA: EL DESARROLLO HUMANO.
}

\author{
Miguel Angel Rubio Gandía. \\ Universidad de Granada. España.
}

\section{I.-INTRODUCCION.}

La cuenca del mediterráneo presenta con claridad las diferencias en su desarrollo existentes entre el Norte y el Sur; los países situados al Norte del Mediterráneo y al Sur del continente europeo conocen un mayor desarrollado que los situados al Sur del Mar y Norte de Africa.

Las diferencias son importantes aunque con el paso del tiempo hay una débil tendencia a reducir la diferencia de desarrollo entre ambas zonas.

En los dos últimos decenios el mundo ha experimentado cambios de gran alcance; gracias a los esfuerzos nacionales y de la comunidad de naciones se ha avanzado mucho en esferas importantes para el bienestar humano. Sin embargo, los países en vías de desarrollo continúan con graves dificultades económicas en un entorno económico internacional desfavorable; hay modalidades insostenibles de producción y de consumo, problemas de población, ecológicos y de muchos tipos que amenazan e hipotecan el bienestar de generaciones futuras. En la actualidad la población se estima en unos 5.600 millones de habitantes, la tasa de crecimiento tiende a disminuir pero el número de personas aumenta de forma absoluta en 86 millones al año, con una mayor participación de los países menos desarrollados. En el Mediterráneo occidental se sigue esa misma tendencia, mayor aumento de población en los países menos desarrollados, Marruecos, Argelia y Túnez; y menor aumento en España.

Se espera asimismo un incremento del éxodo de las zonas rurales a las urbanas; para el año 2.015 se calcula que el $56 \%$ de la población mundial 
vivirá en zonas urbanas, cuando en 1994 ese porcentaje era inferior al 45\%; precisamente, se agravará esa circunstancia en los países en vías de desarrollo, donde la población urbana en 1975 suponía el 26\% del total y se espera que llegue al $50 \%$ el año 2015 , con todos los problemas de infraestructura y servicios sociales que no podrán evolucionar al mismo ritmo que se desarrolla la urbanización de la población.

Todos los problemas emanados de la evolución de la población han sido analizados en la Conferencia Internacional de la Población y el Desarrollo celebrada en El Cairo, en septiembre de 1994. Las conclusiones de esta Conferencia, promovida por la Organización de las Naciones Unidas, así como la publicación del Programa de las Naciones Unidas para el Desarrollo (PNUD), "Informe sobre Desarrollo Humano - 1994", junto con la publicación "Estado de la población mundial - 1994" del Fondo de Población de las Naciones Unidas (FNUAP) y las Actas del Congreso "Explosión demográfica, empleo y trabajadores emigrantes en el Mediterráneo occidental", celebrado en febrero de 1990 en la Universidad de Granada; estas han sido las fuentes que nos han servido para la elaboración de este trabajo.

Las actividades cotidianas de todos los seres humanos, comunidades y países guardan estrecha relación con los cambios demográficos, las modalidades y los niveles de utilización de los recursos naturales, el estado del medio ambiente, el ritmo y la calidad del desarrollo económico y social. La pobreza persistente y generalizada y las graves desigualdades sociales entre hombres y mujeres tiene una importante influencia en los datos demográficos referentes al crecimiento, la estructura y la distribución de la población. Aunque se aprecia una disminución de las tasas de natalidad en muchos países en vías de desarrollo, el volumen total de la población mantiene un alto incremento; dado el predominio de jóvenes en la estructura de la población, es previsible, que en los próximos decenios muchos países registren aumentos importantes de la población en términos absolutos.

El desarrollo sostenible exige la viabilidad a largo plazo de la producción y el consumo en relación a todas las actividades económicas para utilizar los recursos de la forma más racional; hay que integrar la población en estrategias económicas que permitan aumentar la calidad de vida de los habitantes, promuevan la justicia social y eliminen la pobreza. Es necesario, por tanto, que la voluntad política de los gobernantes aplique estrategias integradas de población y desarrollo, con modelos sostenibles de producción que eliminen políticas demográficas inadecuadas; los países en vías de desarrollo soportarán casi todo el crecimiento de la población mundial en el futuro y se encontrarán con graves dificultades para mejorar la calidad de vida de sus 
poblaciones de manera sostenible; la pobreza está estrechamente relacionada con la inadecuada distribución espacial de la población. Hay una íntima relación entre población, progreso económico, pobreza, protección del medio ambiente y modalidades de consumo y producción.

Entre las prioridades del desarrollo humano se deben incluir la eliminación de las desigualdades entre la mujer y el hombre, evitar las barreras existentes para la mujer en el mundo laboral, promover su participación en los recursos económicos, incrementar su preparación, mejorar su posición social, aumentar el control en la salud reproductiva, incluida la planificación familiar; en definitiva, conseguir que la mujer pueda mejorar su situación y contribuya de la forma más eficiente al desarrollo sostenible de la economía. La educación es un medio indispensable para conseguir dar a la mujer los conocimientos, aptitudes y confianza en si misma para participar en el proceso de desarrollo, indispensable para conseguir una evolución positiva sostenible; en la actualidad, en la mayoría de las regiones del mundo la mujer recibe un trato discriminatorio en el proceso educativo, percibe menos educación académica que el hombre y no se le reconocen sus aptitudes y capacidades, poniendo en ocasiones en peligro su bienestar y su salud por esa situación, que no es consecuencia de una postura machista del hombre sino de una situación patriarcal, una carga atávica, unas costumbres ancestrales que hace más difícil su solución, porque son consideradas normas inamovibles, aceptadas tácitamente, de forma voluntaria por la mayoría de la población, tanto hombres como mujeres, opuestos a cambios sociales que atenten contra las costumbres tradicionales; exige un esfuerzo grande, profundo y prolongado en el campo de la educación para vencer esa situación de discriminación femenina que difícilmente puede obtenerse con simples disposiciones legales sino se erradica de las costumbres y de la propia conciencia.

En la actualidad existen unos 960 millones de analfabetos adultos en el mundo, de los cuales las dos terceras partes son mujeres; de un total de 130 millones de nińos que no van a la escuela primaria, el $70 \%$ son niñas, unos 91 millones; la discriminación continúa aunque hay pasos efectivos realizados para cambiar la situación y eliminar todo aquello que discrimine a la mujer en su deseo de conseguir todos sus derechos, su plena realización, eliminar las prácticas diferenciales que en el mercado laboral perjudican a la mujer, tener los mismos derechos y deberes que los hombres, evitar todo tipo de abuso, acoso, violencia y explotación. Los cambios de los conocimientos, las aptitudes y el comportamiento de hombres y mujeres es un requisito indispensable para el logro de una colaboración armoniosa entre hombres y mujeres; el hombre tiene un papel importante en el logro de la igualdad de los sexos, dado el papel preponderante que ocupa en la mayoría de los países 
en casi todas las esferas de la vida; el objetivo debe ser promover la igualdad de los sexos en todos los aspectos incluida la vida familiar y comunitaria, con una mayor participación del hombre en la vida familiar y una mayor integración de la mujer en la vida de la comunidad.

La evolución de la población en el mundo conoce en la actualidad el crecimiento más alto que nunca tuvo en cifras absolutas, unos 86 millones anuales; la tendencia demográfica en la mayoría de los países avanza hacia unas bajas tasas de natalidad y de mortalidad, pero a velocidades diferentes; en el quinquenio 1986-1990 el promedio de fecundidad fue en Italia de 1,3 niños por mujer, mientras que en Ruanda fue de 8,5; la esperanza de vida al nacer en ese mismo período fue en Japón de 78,3 años, mientras que en Sierra Leona fue de 41 años. La disparidad entre los países y regiones en lo concerniente a natalidad y mortalidad influye de forma decisiva en el tamaño y distribución regional de la población mundial y en su desarrollo económico. Se prevé que en el período comprendido entre 1995 y 2015 la población de las regiones menos desarrolladas aumentará en 1.727 millones, frente a los sólo 120 millones durante el mismo período en las regiones más desarrolladas. Es necesario obtener una evolución demográfica rápida para conseguir un mayor equilibrio, respetando los derechos humanos, entre las tasas demográficas y las metas sociales, económicas y ambientales que provocarían un crecimiento económico y un desarrollo sostenible. Los países deben adoptar las medidas necesarias para conseguir un óptimo en su tendencia demográfica para el desarrollo económico y social, movilizar para conseguir ese objetivo todos los sectores de la sociedad; entre esas medidas deben contarse la distribución de la población, con un estudio racional de la movilidad de la población, fundamentalmente las migraciones de los medios rurales a los urbanos; para el año 2005 se prevé que más de la mitad de la población mundial residirá en zonas urbanas; el proceso de urbanización es un aspecto intrínseco del desarrollo económico y social; en la actualidad todos los páses, desarrollados o no, pasan de ser sociedades rurales a sociedades urbanas; las ciudades son centros de crecimiento económico y proporcionan el impulso que necesita el cambio socio-económico y la innovación; la urbanización tiene consecuencias importantes para la vida de las personas. Lo gobiernos deben tener una política de distribución de la población que tenga en cuenta los efectos que dicha distribución puede tener en el desarrollo socio-económico, pero con el respeto debido al derecho de cada persona a vivir y trabajar en el lugar de su elección; deben los gobiernos procurar que los objetivos de la política de distribución de la población sean compatibles con el desarrollo económico y con los derechos humanos; debe reducirse la parcialidad hacia las zonas urbanas y el desarrollo rural aislado con estímulos e 
incentivos para la redistribución de industrias de zonas urbanas a zonas rurales y promocionar el desarrollo económico de las zonas rurales.

Cada vez se está tomando una mayor conciencia sobre la situación de las personas desplazadas, necesitan protección, asistencia, sean desplazadas voluntarias u obligadas, por razones económicas o políticas; debe ponerse fin a toda forma de emigración forzosa, las migraciones exteriores suponen la pérdida de recursos humanos para los países de emigración, aunque tanto el emisor como el receptor pueden beneficiarse de la migración; para que sea positiva se deben tener en cuenta las limitaciones económicas del país de acogida, el impacto de la migración en la sociedad receptora y las repercusiones en los países de origen. Se debe facilitar el proceso de integración del desplazado en el país de acogida y el proceso de reintegración de aquellos que vuelven a su país de origen. En los últimos decenios se ha incrementado el nivel de educación en todo el mundo, aunque continúan existiendo países y minorías de población, como las mujeres, que no se benefician de esta nueva situación; el analfabetismo y la falta de escolaridad es mayor en las mujeres y niñas que en los hombres y niños; la enseñanza es un factor importante del desarrollo y un componente decisivo del bienestar; hay una interdependencia grande entre educación y cambios demográficos y sociales; una relación estrecha entre educación, nupcialidad, fecundidad, actividad económica, mortalidad y movilidad. No es compatible una política de desarrollo sostenido con una situación de fragilidad educativa por no desarrollar los medios oportunos para escolarizar a todos los niños, evitar discriminaciones de cualquier tipo, sobre todo hombres y mujeres, e invertir en capital humano los recursos necesarios que serán muy rentables a largo plazo para el conjunto de la sociedad que hace el esfuerzo y para los beneficiados por esa política que obtendrán una mayor realización desde el primer momento.

Todas estas medidas generan una necesidades financieras tan importantes que necesitan de una colaboración internacional unida al esfuerzo de los propios paises interesados e incluso organizaciones no gubernamentales, locales, nacionales e internacionales, para fomentar una colaboración efectiva entre todos los niveles gubernamentales o no. El desarrollo de los países pobres beneficia en primer lugar a los países interesados pero a los países ricos le suponen también un gran beneficio, se evitan problemas sociales y económicos, falta de seguridad, incremento de la producción y del consumo; en conjunto un beneficio compartido por paises pobres y ricos, más palpable en zonas de fricción donde geográficamente se encuentran situados muy próximos países desarrollados y países en vías de desarrollo, por lo que los problemas derivados de ambas situaciones socio-económicas se multiplican por la proximidad geográfica entre ellos. 


\section{II.-INDICADORES DE POBLACIÓN Y SOCIALES.}

La proximidad geográfica ha producido unos contactos continuos a lo largo de la historia entre el Sur europeo y el Norte africano, mayores cuanto más corta era la distancia, como ocurre en la península Ibérica y el Magreb, separados por unos pocos kilómetros del Estrecho de Gibraltar; contactos debidos a invasiones mutuas han dejado una profunda huella en la historia, costumbres, toponimia, etc. del Magreb en España y viceversa. Por esta circunstancia hemos considerado oportuno hacer un análisis comparativo sobre la población y el desarrollo humano en España y el Magreb.

Unos primeros datos nos pueden dar idea de la evolución de la población en esta región del mundo y la comparación con el conjunto europeo, africano y mundial; primero expondremos unos indicadores de población que nos sirvan de centro de interés para analizar y comentar la situación de la población; a continuación expondremos unos indicadores sociales que serán motivo de comentarios y conclusiones.

Notas a los cuadro siguientes:

1.-Comprende Portugal, Espana, Italia, antigua Yugoslavia, Albania y Grecia.

2.-Comprende Marruecos, Argelia, Túnez, Libia, Egipto y Sudán.

3.-Comprende Europa, América del Norte, Japón, Australia, Nueva Zelanda y la ex-Unión de Repúblicas Socialistas Soviéticas.

4.-Comprende Africa, América Latina, Asia menos Japón, Melanesia, Micronesia y Polinesia.

Indicadores de población:

\begin{tabular}{|c|c|c|c|c|c|}
\hline PAISES & $\begin{array}{l}\text { Población en } \\
\text { en millones } \\
1994\end{array}$ & $\begin{array}{l}\text { Población } \\
\text { en millones } \\
2025\end{array}$ & $\begin{array}{c}\text { Tasa media } \\
\text { de crecimiento } \\
1990-1995\end{array}$ & $\begin{array}{l}\text { Tasa de } \\
\text { natalidad } \\
\text { por } 1.000 \\
1990-1995\end{array}$ & $\begin{array}{l}\text { Tasa de } \\
\text { mortalidad } \\
\text { por } 1.000 \\
1990-1995\end{array}$ \\
\hline España & 39.2 & 40.6 & 0.2 & 11 & 9 \\
\hline Marruecos & 27.0 & 47.5 & 2.4 & 32 & 8 \\
\hline Argelia & 27.1 & 51.8 & 2.7 & 34 & 7 \\
\hline Túnez & 8.6 & 13.4 & 2.1 & 27 & 6 \\
\hline Sur de Europa & 144.6 & 148.2 & 0,2 & 11 & 10 \\
\hline Europa sin Rusia & 512.0 & 541.8 & 0.3 & 13 & 11 \\
\hline Norte de Africa ${ }^{2}$ & 147.7 & 280.4 & 2.5 & 34 & 9 \\
\hline África & 681.7 & $1,582.5$ & 2.2 & 43 & 14 \\
\hline Regiones más desarrolladas ${ }^{3}$ & $1,237.6$ & $1,403.3$ & 0.5 & 14 & 10 \\
\hline Regiones menos desarrolladas ${ }^{4}$ & $4,427.9$ & $7,069.2$ & 2.0 & 29 & 9 \\
\hline TOTAL MUNDIAL & 5.665 .5 & 8.472 .5 & 1.7 & 26 & 9 \\
\hline
\end{tabular}


EL MAGREB y España: El desarRollo humano

\begin{tabular}{|c|c|c|c|c|c|}
\hline PAfSES & $\begin{array}{c}\text { Esperanza } \\
\text { de vida } \\
1990-1995\end{array}$ & $\begin{array}{c}\text { Mortalidad } \\
\text { infantil } \\
\text { por } 1.000 \\
1990-1995\end{array}$ & $\begin{array}{l}\text { Porcentaje } \\
\text { población } \\
\text { urbana } \\
1992\end{array}$ & $\begin{array}{c}\text { Tasa de } \\
\text { crecimiento } \\
\text { urbano, \% } \\
1992\end{array}$ & $\begin{array}{l}\text { Tasa de } \\
\text { fecundidad } \\
1990-1995\end{array}$ \\
\hline España & 78 & 7 & 79 & 0.7 & 1.4 \\
\hline Marruecos & 63 & 68 & 47 & 3.4 & 4.4 \\
\hline Argelia & 66 & 61 & 53 & 4.3 & 4.9 \\
\hline Túnez & 68 & 43 & 57 & 3.2 & 3.4 \\
\hline Sur de Europa ${ }^{1}$ & 76 & 12 & 67 & 0.9 & 1.5 \\
\hline Europa sin Rusia & 75 & 10 & 74 & 0.7 & 1.7 \\
\hline Norte de $A_{\text {frica }}{ }^{2}$ & 61 & 69 & 45 & 3.5 & 4.7 \\
\hline Africa & 53 & 95 & 33 & 4.6 & 6.0 \\
\hline Regiones más desarrolladas ${ }^{3}$ & 75 & 12 & 73 & 0.9 & 1.9 \\
\hline Regiones menos desarrolladas ${ }^{4}$ & 62 & 69 & 35 & 3.7 & 3.6 \\
\hline TOTAL MUNDIAL & 65 & 62 & 44 & 2.7 & 3.3 \\
\hline
\end{tabular}

Fuente: Estado de la población mundial, 1994. Fondo de Población de las Naciones Unidas (FNUAP).

Queremos aclarar las dificultades que encierran las prospecciones demográficas por la inseguridad del campo donde nos movemos; hay muchas dificultades para responder con números a problemas biológicos; son aproximaciones siempre dispuestas a correcciones dictadas por la realidad y no por las prospecciones, aunque estas siempre tendrán el innegable valor de acercarnos a lo que puede ser aunque luego no sea, a conocer algo más que desconoceríamos sino las hubiésemos hecho. Esta reflexión viene a propósito de la evolución de la población del año 1994 al año 2025 ¿ Será así?, puede ser, seguro si continúa la población con una evolución idéntica a la actual. Pero la población es algo no sometido a reglas fijas. ¡Como se podría pensar hace una centuria que la población llegaría a reducirse en cifras absolutas sin hambres, guerras, ni epidemias, sólo por la libre voluntad de reducir la natalidad de una forma drástica precisamente en las naciones más ricas del mundo! Difícilmente se podía prever, pero ha sido así.

Nuestros comentarios giran en torno a lo previsible, por lo tanto conocido; no a lo imprevisto y desconocido; en esa línea nos encontramos con un aumento de la población mundial del año 1994 al 2025 que pasa de 5.665,5 millones a 8.472,4 millones, lo que supone un aumento global de 2.806,9 millones en 31 años, con un aumento medio anual de 90,5 millones; un 
incremento muy elevado, del $49,5 \%$; elevado pero irregular como muestra la tabla de incremento que exponemos a continuación:

Aumento de población.

\begin{tabular}{|c|c|c|c|c|}
\hline PAISES & $\begin{array}{c}\text { Población en } \\
1994 \\
\text { (millones) }\end{array}$ & $\begin{array}{l}\text { Población } \\
2025 \\
\text { (millones) }\end{array}$ & $\begin{array}{l}\text { Diferencia } \\
\text { millones }\end{array}$ & $\begin{array}{l}\text { Aumento } \\
(\%)\end{array}$ \\
\hline Espania & 39.2 & 40.6 & 1.4 & 3.57 \\
\hline Marruecos & 27.0 & 47.5 & 20.5 & 75.92 \\
\hline Argelia & 27.1 & 51.8 & 24.7 & 91.14 \\
\hline Túnez & 8.6 & 1.4 & 4.8 & 55.81 \\
\hline Sur de Europa & 144.6 & 148.2 & 3.6 & 2.48 \\
\hline Europa sin Rusia & 512.0 & 541.8 & 29.8 & 5.82 \\
\hline Norte de Africa & 147.7 & 280.4 & 132.7 & 89.84 \\
\hline Africa & 681.7 & 1582.5 & 900.8 & 132.14 \\
\hline Regiones más desarrolladas & 1237.6 & 1403.3 & 165.7 & 13.38 \\
\hline Regiones menos desarrolladas & 4427.9 & 7069.2 & 2641.3 & 59.65 \\
\hline TOTAL MUNDIAL & 5665.5 & 8472.5 & 2807.0 & 49.54 \\
\hline
\end{tabular}

Fuente: Elaboración propia con datos del Fondo de Población de las Naciones Unidas (FNUAP).

Los datos son elocuentes por ellos mismos; podemos obtener una serie de conclusiones deducidas de ellos que resumidas son las siguientes:

1.-Incremento elevado de la población, un $49,54 \%$ en 31 años, lo que supone a ese ritmo duplicar la población en 63 años, a pesar de la caída de la natalidad en algunas regiones.

2.-La gran diferencia existente en el incremento de la población entre regiones desarrolladas, con un aumento del $13.38 \%$, con las regiones menos desarrolladas que alcanzan el 59.65\%.

3.-Esa diferencia se agudiza cuanto más ricas o pobres sean respectivamente, como es el caso de Europa con un aumento de $5.82 \%$ que contrasta fuertemente con Africa que tiene un incremento del $132.14 \%$.

4.- - La gran diferencia expuesta en el apartado anterior se reduce en el caso de Europa meridional y Africa del Norte, con un $2.48 \%$ y $89.84 \%$ respectivamente; sigue siendo una diferencia muy acusada. 
5.-El continente africano, zona deprimida económicamente, conoce un incremento de población muy superior al incremento medio de las regiones menos desarrolladas, el $132.14 \%$ y el $59.65 \%$ respectivamente, más del doble, lo que nos hace reflexionar sobre el subdesarrollo del continente africano en el conjunto de las regiones menos desarrolladas.

6.-En el Magreb, la nación más oriental, Túnez tiene un aumento previsible de población por debajo de la media de los países menos desarrollados, $55.81 \%$ y $59.65 \%$ respectivamente; no ocurre lo mismo con Argelia y Marruecos, que con el $91.14 \%$ y el $75.92 \%$ respectivamente, supone un porcentaje muy superior a la media mundial $49.54 \%$ y a la media de las regiones menos desarrolladas, $59.65 \%$, pero muy inferior a la media del continente africano, $132.14 \%$, aunque próxima a la media del Norte de Africa, $89.94 \%$.

7.-La estabilización de la población en los países desarrollados y la tendencia actual del total de los países a la reducción paulatina de la natalidad hace prever una estabilidad a medio y largo plazo, porque disminuye la natalidad y porque el envejecimiento de la población supondrá un incremento natural de la mortalidad, por lo que podrá haber incluso una disminución en países desarrollados donde la caida de la natalidad ha sido muy fuerte, a no ser que se recupere la natalidad. Concretamente, en el caso de España hay un año bisagra, el 2008, en el que según las previsiones se iniciaría el descenso de la población; ese año España tendría 41.210 .000 habitantes, pero el año 2.010 con el inicio del descenso absoluto de la población España tendría 41.180.000 habitantes.

8.-España y los países del Magreb reflejan en su evolución demográfica el estado actual socio-económico de país desarrollado el primero y en vías de desarrollo los segundos, más acentuados en el caso de Argelia, menos en el de Túnez y en una posición intermedia el Reino de Marruecos.

9.-El gran aumento de la población en el continente africano, unido al reducido aumento en Europa puede crear, y de hecho ya ha comenzado, un grave problema de superpoblación en una zona donde sus recursos económicos no permiten alimentar a tanta población que lógicamente tenderá a ocupar espacios más ricos donde pueda encontrar aquello que no encuentra en sus países de origen, más cuando estas zonas ricas tienden a disminuir su población.

10.-La situación geográfica de la península Ibérica la hace muy sensible a lo afirmado en el apartado anterior, por lo que la responsabilidad de España para su bien y la de los países vecinos es la de colaborar al máximo para resolver el problema, con ayudas al desarrollo, con previsiones de inmigraciones, colaborando con los países del Magreb, sobre todo con Marruecos y con la Comunidad Europea, en la solución de este importante problema. 
11.-Las dificultades derivadas de la situación socio-político-religiosa que atraviesa el mundo musulmán en la actualidad, caso de Argelia, puede agudizar el problema planteado en el apartado anterior.

12.-La elevada natalidad de los países en vías de desarrollo crea una pirámide regular de población, con una base amplia, pero clase pasiva, ya que son niños; una población joven abundante que provoca una mayor fertilidad y una necesidad mayor de puestos de trabajo para los jóvenes que acceden al mercado laboral; este aspecto lo analizaremos con mayor amplitud en el último apartado del presente estudio.

Indicadas las reflexiones anteriores, exponemos otros datos estadísticos con indicadores sociales indicativos del desarrollo humano en la zona analizada.

Indicadores sociales.

\begin{tabular}{|l|c|c|c|c|c|c|}
\hline P A I S E S & $\begin{array}{c}\text { Alfabetización } \\
\text { de adultos } \\
(\mathrm{H} / \mathrm{M}) \\
1990\end{array}$ & $\begin{array}{c}\text { Partos atendidos } \\
\text { por sanimarios } \\
(\%) \\
1983-92\end{array}$ & $\begin{array}{c}\text { Usuarios de } \\
\text { Planificaión } \\
\text { Familiar } \\
1975-93\end{array}$ & $\begin{array}{c}\text { Producción alimen- } \\
\text { taria per cápita } \\
(1979-81=100) \\
19891\end{array}$ & $\begin{array}{c}\text { Tierra } \\
\text { cultivable } \\
\text { (Hab./Ha.) } \\
1989\end{array}$ & $\begin{array}{c}\text { PNB per } \\
\text { cápita } \\
\text { (dólares EEUU) } \\
1991\end{array}$ \\
\hline España & $97 / 93$ & 96 & 59 & 113 & 0.2 & 12.450 \\
Marruecos & $61 / 38$ & 26 & 42 & 140 & 1.0 & 1.030 \\
Argelia & $70 / 46$ & 15 & 51 & 107 & 0.8 & 1.980 \\
Túnez & $74 / 76$ & 69 & 50 & 113 & 0.4 & 1.500 \\
\hline
\end{tabular}

Fuente: Estado de la población mundial, 1994. Fondo de Población de las Naciones Unidas (FNUAP).

Hemos seleccionado estos indicadores sociales por diversas razones, como la relación que tienen con el nivel cultural de la población, índice de alfabetización, relación con la salud en un aspecto tan importante como la salud genésica; la relación con la evolución de la población es el motivo de la elección del índice de usuarios de planificación familiar; el equilibrio entre población y bienes de consumo, sobre todo alimentos, es la razón del índice sobre producción alimentaria per cápita; las tierras cultivables, con un índice que relacionan habitantes con hectáreas, es importante, más en unos países, los del Magreb, donde el sector primario tiene aún una influencia económica decisiva; finalmente, el PNB per cápita, en dólares de EEUU, no necesita presentación de su importancia para poder conocer la situación socio-económica de los países que tratamos y haberlo elegido como un importante indicador social. 
Nuevas reflexiones surgen con estos indicadores sociales, unas nacidas de si mismas y otras como consecuencia de la comparación entre los tres países del Magreb y de estos con España. Resumidas son las siguientes:

1.-La alfabetización, entendida como el uso del lenguaje escrito, se aproxima al total de la población en España; los países del Magreb han superado cotas bajas de analfabetismo, pero continúan teniendo mucho campo por delante para erradicar esa plaga.

2.-La alfabetización es muy superior en los hombres del Magreb que en las mujeres; los hombres tienen una media del $68.33 \%$ de alfabetos, mientras que las mujeres quedan muy lejos de ellos con el $46.66 \%$. La situación socio-económica de la mujer en el mundo musulmán puede explicar esta gran diferencia.

3.-El recurso a los sanitarios en el momento del paro indica el nivel sanitario del país, junto con el nivel cultural de la población; mientras en España casi todos los partos son atendidos por profesionales sanitarios, en los tres países del Norte de Africa hay una gran diferencia, del $69 \%$ en Túnez al $15 \%$ en Argelia, dato no previsible dada la política de desarrollo social llevada a cabo por los gobiernos argelinos desde la independencia; las costumbres influir de forma considerable en este aspecto.

4.-Hay una mayor homogeneidad en el uso de la planificación familiar entre España y el Magreb. Las creencias religiosas pueden tener una influencia decisiva en este apartado.

5.-La búsqueda de equilibrio entre la población y los alimentos puede ser motivo del incremento generalizado de productos alimenticios per cápita; aunque se cultivan menos tierras la tecnologia ha hecho posible el incremento de la producción con un menor espacio cultivado. Marruecos ha evolucionado muy favorablemente en este campo mientras que España, Argelia y Túnez tienen las tres un incremento parecido.

6.-La mayor densidad de población en España es la causa de la más baja cantidad de tierra cultivada por habitante, Túnez multiplica por dos, Argelia por cuatro y Marruecos por cinco la tierra cultivable por habitante con relación a España.

7.-Hay unas diferencias muy grandes en el PNB per cápita entre España y los países magrebíes. Aunque el poder adquisitivo es un elemento básico para conocer el valor real del PNB, la diferencia es de tal magnitud que nos indica con claridad el desigual desarrollo entre ambas zonas del Mediterráneo.

Las reflexiones expuestas nos llevan a la conclusión de la urgencia con que deben tomarse las medidas para reducir las grandes diferencias entre ambas 
zonas, con una ayuda masiva internacional que colabore en el desarrollo del Magreb; ayuda que debe ir encaminada a la fijación de la población en sus lugares de origen ya que la emigración debe ser una solución excepcional y a corto plazo; es más fácil y más humano mover los capitales y no las personas.

\section{III.-INDICE DE DESARROLLO HUMANO.}

El Informe sobre Desarrollo Humano, 1994, publicado para el Programa de las Naciones Unidas para el Desarrollo (PNUD) recoge unos interesantes índices que permiten conocer la evolución de los diferentes países del mundo, tanto los desarrollados como los que se encuentran en vías de desarrollo, diferenciándolos por su alto, mediano o bajo desarrollo económico. Lo consideramos una aportación básica para conocer el estado de la cuestión en el momento de la Conferencia Internacional sobre la Población y el Desarrollo de El Cairo de 1994. Lo primero que debe conocerse es el problema que se intenta resolver para buscar soluciones. Los datos son abundantes y corresponden a los años 1991 y, sobre todo, al 1992; son de gran actualidad, de ahí el gran interés que suscitan. Algunos datos se han expuesto en páginas anteriores pero por corresponder a unos años diferentes $y$ por proceder de fuentes distintas nos permitiremos repetir algunos para poder hacer una mejor comparación. Las diferencias que se encuentren entre datos anteriores y los que ahora presentamos son consecuencia de las distintas fuentes y cronología.

Indice de desarrollo humano:

\begin{tabular}{|c|c|c|c|c|}
\hline PAISES & $\begin{array}{c}\text { Esperanza de } \\
\text { vida al nacer } \\
\text { (2hios) } \\
1992 \\
\end{array}$ & $\begin{array}{l}\text { Tase de alfa. } \\
\text { becismo de } \\
\text { adultos }(\%) \\
1992\end{array}$ & $\begin{array}{l}\text { Promedio de } \\
\text { anos de } \\
\text { escolaridad } \\
1992\end{array}$ & $\begin{array}{c}\text { PIB real } \\
\text { per cepira } \\
\text { (ddiarses) } \\
\text { 1991 }\end{array}$ \\
\hline Alto desarrollo humano & 74.1 & 97.3 & 9.8 & 14.000 \\
\hline Mediano desarrollo humano & 78.0 & 80.4 & 4.8 & 3.420 \\
\hline Bajo desarrollo humano & 55.8 & 47.4 & 2.0 & 1.170 \\
\hline España & 77.4 & 98.0 & 6.9 & 12.670 \\
\hline Marruecos & 62.5 & 52.5 & 3.0 & 3.340 \\
\hline Argelia & 65.6 & 60.6 & 2.8 & 2.870 \\
\hline Túnez & 67.1 & 68.1 & 2.1 & 4.690 \\
\hline
\end{tabular}

Fuente: Informe sobre el Desarrollo Humano, 1994. Programa de las Naciones Unidas para el Desarrollo (PNUD). 
En la misma dirección que los datos expuestos anteriormente, nos encontramos con unos índices que confirman lo dicho pero reduciendo las diferencias entre los países del Magreb y de estos con España. Los tramos altos, mediano y bajo desarrollo humano son índices medios de los países situados en esos tramos.

Las reflexiones que podemos obtener de estos índices de desarrollo humano son las siguientes:

1.-En esperanza de vida al nacer España se encuentra en el índice del alto desarrollo humano, mientras que los tres países del Magreb se hallan dentro del índice del mediano desarrollo humano.

2.-La tasa de alfabetismo, siempre con datos de 1992, menos en el PIB que es de 1991, España se encuentra situada en el tramo superior; los palses magrebíes están comprendidos entre los tramos mediano y bajo.

3.-El apartado promedio de años de escolaridad, sitúa a España en un índice relativamente bajo, entre los tramos de mediano y alto desarrollo humano. La entrada en vigor en España de la Enseñanza Secundaria Obligatoria (ESO) ha incrementado en dos años la enseñanza obligatoria, que comprende desde los seis a los dieciséis años de edad, que supone diez años de obligatoriedad escolar, aunque el promedio sea un poco inferior. En este apartado los tres países africanos analizados se encuentran más próximos al índice de bajo desarrollo humano que al mediano; grave problema de enorme repercusión socio-económico; más extraño en el caso de Túnez, con unos índices más avanzados, y de Argelia, preocupada por los problemas sociales.

4.- - Hay una variación sustancial en los índices correspondientes al PNB y PIB de Marruecos, Argelia y Túnez, más elevado en el segundo que en el primer caso, las diferencias con relación al alto desarrollo humano son grandes aunque se encuentran en torno al índice medio del desarrollo mediano.

La difusión de los medios de comunicación social puede ser considerada un índice del perfil del desarrollo humano por lo que vamos a dar unos datos referidos a la extensión que han alcanzado la prensa, radio y televisión en los cuatro países analizados, la comparación entre ellos y con el resto del mundo. 
Medios de comunicación social:

\begin{tabular}{|l|c|c|c|}
\hline \multicolumn{1}{|c|}{ PA I S E S } & $\begin{array}{c}\text { Difusión de prensa } \\
\text { diaria (por 100 habit.) } \\
1990\end{array}$ & $\begin{array}{c}\text { Televisores } \\
\text { (por 100 habit.) } \\
1990\end{array}$ & $\begin{array}{c}\text { Radios } \\
\text { (por 100 habit.) } \\
1990\end{array}$ \\
\hline Industrializados & 30 & 54 & 113 \\
En vías de desarrollo & 4 & 6 & 18 \\
\hline Total mundial & 9 & 15 & 35 \\
\hline España & 11 & 40 & 31 \\
Marruecos & 1.3 & 7.4 & 21 \\
Argelia & 5.1 & 7.4 & 23 \\
Túnez & 3.7 & 8.1 & 20 \\
\hline
\end{tabular}

Fuente: Informe sobre el Desarrollo Humano, 1994. Programa de las Naciones Unidas para el Desarrollo (PNUD).

Nuevos datos relacionados con el perfil del desarrollo humano y las comunicaciones. Consideramos básica la información para catalogar el nivel cultural y de bienestar de un pueblo, incluso su nivel de libertad; un pueblo informado es más libre, sobre todo si la información es heterogénea, no por su contenido sino por sus diferentes tendencias y no existe una censura previa.

Nuevas reflexiones sobre lo expuesto en el índice de comunicación social nos llevan a las siguientes conclusiones:

1.-Hay una gran diferencia entre los países ricos y pobres en lo referente al uso de los medios de comunicación social, casi multiplicándose por ocho.

2.-España ocupa un lugar intermedio entre los países industrializados y en vías de desarrollo que no corresponde al puesto que ocupa en otros índices de desarrollo humano. Creemos puede ser una consecuencia del régimen político autoritario que hubo en nuestro país durante un largo período del siglo XX (1939-1975).

3.-Marruecos, Argelia y Túnez ocupan un lugar por debajo de la media del total mundial tanto en prensa, como en radio y televisión.

4.- Necesidad de incrementar el uso de los medios de comunicación social, sobre todo los escritos, para conseguir una mejor formación e información, unos ciudadanos más libres.

La situación de la mujer en muchos países ha sido de discriminación con respecto al hombre en todos los aspectos de la vida, tanto educativos 
como laborales, en una sociedad donde ha predominado el régimen patriarcal.

Consideramos de interés conocer algunos aspectos de la situación de la mujer en la actualidad, aunque posteriormente los analicemos con mayor detenimiento en los países norteafricanos, donde por el atavismo y costumbres ancestrales se encuentran en una situación de inferioridad aunque en vías de sufrir un proceso importante de igualación motivado por la educación y por los cambios de mentalidad y costumbres.

Condición de la mujer:

\begin{tabular}{|c|c|c|c|}
\hline PAISES & $\begin{array}{c}\text { Esperanza de vida } \\
\text { al nacer (afios) } \\
\text { (afios) } 1992\end{array}$ & $\begin{array}{c}\text { Promedio de edad al } \\
\text { contraer el ler matrimonio } \\
\text { (arios) 1980-1990) }\end{array}$ & $\begin{array}{l}\text { Parlamento (\% de } \\
\text { escaños ocupado } \\
\text { por mujeres) } 1992\end{array}$ \\
\hline Industrializados & 78.0 & 24.5 & 10 \\
\hline En vías de desarrollo & 64.5 & 20.8 & 11 \\
\hline Total mundial & 67.5 & 21.0 & 11 \\
\hline España & 80.4 & 24.7 & 16 \\
\hline Marruecos & 64.3 & 22.3 & 1 \\
\hline Argelia & 66.6 & 21.0 & 10 \\
\hline Túnez & 68.0 & 24.3 & 4 \\
\hline
\end{tabular}

Fuente: Informe sobre el Desarrollo Humano, 1994. Programa de las Naciones Unidas para el Desarrollo (PNUD).

La esperanza de vida de la mujer, siempre un poco más elevada que la del hombre, conoce en los países vecinos del Magreb un promedio próximo a la media mundial, 66.3 años y 67.5 respectivamente. En el caso de España, la esperanza de vida media al nacer de las mujeres en el año 1992 eran muy elevadas, 80.4 años, muy por encima de los países industrializados, 78 años.

Como la mayor parte de los hijos son legítimos, nacidos en el seno de matrimonios, cuanto más se retrasaba la edad femenina del matrimonio, más se retrasaba el momento de engendrar hijos y este retraso se convierte en una traba a la natalidad; en general, los países norteafricanos tienen una edad más joven para contraer matrimonio las mujeres, media de los tres países, 22.5 años, que en España es 24.7; están por encima de los países en vías de desarrollo, 20.8 años, y de la media mundial, 21 años. La repercusión sobre la natalidad va unida a la utilización mayor o menor de métodos de planifica- 
ción familiar. La presencia de la mujer en la vida política de sus respectivos países en puestos de responsabilidad es inferior en los países musulmanes analizados que en España; el parlamento acoge una media de diputadas del $5 \%$, con un máximo en Argelia del 10\% y un mínimo en Marruecos del 1\%, ambos porcentajes en el año 1992. En España la presencia femenina en el Congreso es mayor, $16 \%$, quizás muy influido por la famosa cuota del $25 \%$ que un importante partido político español puso como norma para los puestos políticos de responsabilidad. En el conjunto mundial la presencia de la mujer es reducida, causa sorpresa que en los países desarrollados sea inferior al total mundial y al correspondiente en los países en vías de desarrollo, el $10 \%, 11 \%$ y $11 \%$, respectivamente.

Otros aspectos indicativos del desarrollo humano se refieren al cine, teléfono y vehículos motorizados; debemos tener presente que el mayor número de vehículos motorizados no indica siempre un nivel de vida más alto ni un desarrollo humano mayor, ni una calidad de vida superior; son sólo unos índices más, significativos todos ellos en su conjunto. También se debe tener presente la influencia que en el mundo musulmán ha tenido en los últimos tiempos las nuevas corrientes ideológicas surgidas del renacer religioso; esto último puede influir de forma decisiva en el desarrollo humano femenino con la especial incidencia que en la mujer tiene las costumbres atávicas de los países musulmanes.

Otros aspectos del desarrollo humano:

\begin{tabular}{|l|c|c|c|c|}
\hline \multicolumn{1}{|c|}{ P A I S E S } & $\begin{array}{c}\text { Asistencia anual al } \\
\text { cine (por persona) } \\
\text { 1988-91 }\end{array}$ & $\begin{array}{c}\text { T(rulos de libros public. } \\
\text { dos (por 100.000 habit.) } \\
\text { 1988-91 }\end{array}$ & $\begin{array}{c}\text { Telfonos } \\
\text { (por 100 habit.) } \\
\text { 1990-92 }\end{array}$ & $\begin{array}{c}\text { Vecliculos motorizados } \\
\text { (por 100 habit.) } \\
1989-90\end{array}$ \\
\hline Industrializados & 2.3 & 74 & 48 & 50 \\
En vias de desarrollo & 3.0 & 5 & 3 & 3 \\
\hline Total mundial & 2.8 & 15 & 13 & 15 \\
\hline España & 2.0 & 100 & 40 & 37 \\
Marruecos & 1.2 & - & 2.7 & 3.6 \\
Argelia & 0.9 & 1.9 & 4.7 & 4.6 \\
Túnez & - & 4.0 & 4.9 & - \\
\hline
\end{tabular}

Fuente: Informe sobre el Desarrollo Humano, 1994. (PNUD) 
En el epígrafe genérico de otros aspectos del desarrollo humano podríamos haber incluido datos concernientes a facetas diversas del quehacer social, tales como urbanización, estadísticas macroeconómicas, salud, delincuencia, empleo, consumo de energía, etc., muy importantes todos para mejor conocer el estado del desarrollo humano de los países analizados, pero la extensión de la comunicación nos impide aumentar los datos y hay que ser selectivos.

Resulta curioso comprobar como la asistencia al cine va en proporción inversa al desarrollo de los países, más desarrollo menos asistencia, como lo indica el 2.3 de los países industrializados, inferior en 0.7 de los países en vías de desarrollo que alcanzan el 3.0. El caso español es normal en el conjunto mundial, no así el de Marruecos y Argelia, paises en desarrollo que tienen una media de asistencia de 1.05 , un tercio de la media de los páses no desarrollados. Los libros publicados son indicativos del desarrollo cultural de los países que los publican, aunque en ocasiones parte de esas publicaciones no conocen la adecuada difusión. Argelia y Túnez tienen un índice muy bajo, el 2.95, que contrasta con el índice español muy elevado de 100; e incluso con la media de los países en desarrollo, el 5; la media mundial, el 15; y los paises desarrollados, 74.

El teléfono es un medio de comunicación fundamental para el desarrollo económico y las relaciones humanas; no es necesario destacar su importancia como índice del desarrollo humano; la diferencia entre los países del Magreb y España es muy elevada, 4.1 y 40, respectivamente; con relación a los países industrializados, 48 , la diferencia se acentúa, e incluso es inferior a la media mundial, 13; pero superior a la media de los países en desarrollo, 3; este último dato nos indica la gran distancia existente entre países industrializados, 48, y paises en vías de desarrollo, 3 .

Cuando los vehículos motorizados han pasado de ser un bien de consumo a ser una plaga que amenaza el bienestar, la convivencia y la vida, creemos que no puede ser considerado un índice de desarrollo humano el número de vehículo motorizados, a no ser que lo sea en proporción inversa, cuanto menos vehículos menos desarrollo humano. Independiente de las reflexiones expuestas sabemos la importancia que en el desarrollo económico de un país tiene su parque móvil; la escasez de vehículos en Marruecos y Argelia, sólo 4.1 por 100 habitantes en el bienio 1989-1990; contrasta con España, 37; con los paises industrializados, 50 , con el total mundial, 15 y es un poco más elevado que la media de los países en desarrollo, 3. Este índice nos indica el escaso desarrollo económico de los pueblos estudiados al Sur del Mediterráneo. 
No queremos terminar este apartado sin volver a insistir en un tema de gran importancia; no puede existir una convivencia normal entre pueblos vecinos con desarrollos económicos muy diferentes; por bien de ambas comunidades, por una convivencia normalizada entre los vecinos, debe incrementarse el desarrollo de los pueblos pobres para evitar zonas de fricción, de las que hay muchos ejemplos en la geografía mundial. No pueden mantenerse a los pueblos al borde de la desesperación que puede provocar en cualquier momento un estallido de incalculables consecuencias. En la situación actual la tensión es máxima y juega un importante papel la llegada al mercado de trabajo de nuevas generaciones, mayores en países con predominio de población joven, como es el caso de Marruecos, Argelia y Túnez, en que su evolución demográfica ha provocado la actual situación. El tema es de tanta importancia que es el núcleo del próximo apartado del presente estudio.

\section{IV.-LA POBLACION Y EL MERCADO DE TRABAJO EN EL MAGREB.}

Nuestros vecinos norteafricanos tienen un escaso desarrollo económico, pero resulta muy atractivo para nosotros por sus muchas relaciones con el sur de Europa y, concretamente, con España. Los aspectos referidos a la población, mercado de trabajo, demanda de empleo, entre otros, son de interés para España.

El problema del empleo constituye una cuestión grave e importante en los países del Magreb o, en todos los países desarrollados y no desarrollados del mundo; el aumento en los niveles de paro y subempleo es la consecuencia de la demanda de puestos de trabajo muy superior a la capacidad de oferta gestada por parte de su economía.

Una serie de circunstancias económicas surgidas desde su independencia, Marruecos y Túnez en el año 1956; Argelia tras una sangrienta guerra, el año 1962; con un estado nuevo que ocupaba un papel muy destacado e importante en la vida política social y económica; con un predominio muy marcado del sector primario de la económica, agricultura, sobre el secundario y terciario; aunque la industria y los servicios conocieron una notable progresión.

$\mathrm{El}$ aumento del empleo fue insuficiente para absorber la creciente fuerza de trabajo surgida de su población joven, a pesar que la mujer aún no había irrumpido como fuerza laboral; existía mucho desempleo y la tasa de paro alcanzó entre un 15 y un $20 \%$ en Túnez y Marruecos; Argelia conoció tasas menores aunque si tenía un elevado paro encubierto, producto del subempleo. En la actualidad, año 1995, no nos parece a los españoles exce- 
siva la tasa de desempleo del 15 al $20 \%$, ya que es inferior a la de varias regiones españolas, como Andalucía. El crecimiento anual medio de la fuerza de trabajo ha evolucionado como indicamos a continuación:

Crecimiento anual medio de la fuerza de trabajo:

\begin{tabular}{|l|c|c|c|}
\hline \multicolumn{1}{|c|}{ P A f S E S } & $1965-1980$ & $1980-1985$ & $1985-2000$ \\
\hline Marruecos & 2.9 & 3.3 & 3.1 \\
Argelia & 2.8 & 3.1 & 2.8 \\
Túnez & 2.2 & 3.6 & 3.7 \\
\hline España & 0.6 & 1.3 & 0.8 \\
\hline
\end{tabular}

Fuente: "Explosion demografica, empleo y trabajadores emigrantes en el Mediterráneo occidental". Congreso, Febrero 1990. Universidad de Granada, 1993.

El aumento en el Magreb es muy superior al español con lo que el problema en esa zona tiende a agravarse, más en Marruecos y Argelia que en Túnez donde el incremento fue inferior en el período 1965-1980, aunque después ha superado a sus vecinos pero ya en mejores condiciones económicas.

Distribución de la fuerza de trabajo (\%):

\begin{tabular}{|l|c|c|c|c|c|c|}
\hline \multirow{2}{*}{\multicolumn{2}{|c|}{ PAIS E S }} & \multicolumn{2}{|c|}{ AGRICULTURA } & \multicolumn{2}{c|}{ INDUSTRIA } & \multicolumn{2}{c|}{ SERVICIOS } \\
\cline { 2 - 7 } & 1965 & 1980 & 1965 & 1980 & 1965 & 1980 \\
\hline Marruecos & 61 & 46 & 15 & 25 & 24 & 29 \\
Argelia & 57 & 31 & 17 & 27 & 26 & 42 \\
Túnez & 49 & 35 & 22 & 36 & 29 & 29 \\
\hline Espania & 33 & 17 & 35 & 37 & 32 & 46 \\
\hline
\end{tabular}

Fuente: "Explosión demográfica, empleo y trabajadores emigrantes en el Mediterráneo occidental". Congreso, Febrero 1990. Universidad de Granada, 1993.

La tendencia a la normalización estructural de la fuerza de trabajo propia de países en vías de desarrollo pero aún muy distantes de países desarroIlados como España. En Marruecos no se ha desarrollado lo suficiente el sector secundario, por lo que la capacidad de creación de empleo industrial no ha aumentado lo suficiente, la agricultura continúa siendo la principal acti- 
vidad de la población activa. En Argelia se ha incrementado mucho el sector servicios con una Administración muy fuerte y centralizada, con una importante disminución de la población activa en el sector primario.

La emigración ha sido la solución para el exceso de mano de obra existente en la zona, pero la crisis económica de 1973 ha reducido las posibilidades migratorias por lo que se ha incrementado el desequilibrio entre oferta y demanda de puestos de trabajo. Los tres países del Magreb, Marruecos, Argelia y Túnez, con estrategias de desarrollo diferentes, han sufrido de forma muy pronunciada la crisis económica de los países desarrollados de los años setenta y la crisis económica de los países en vías de desarrollo de la década de los ochenta.

Marruecos ha tenido que adaptar su economía a un rápido crecimiento de la población; el año 1960 la población marroquí era de 11.626 .000 habitantes, el año 1971 eran ya 15.379 .000 y en 1982 ascendían a 20.419.000 habitantes. Este rápido aumento de la población incrementó de forma considerable la población activa, distribuida de la forma siguiente:

Clasificación por sectores de producción de la población activa en Marruecos:

\begin{tabular}{|l|c|c|}
\hline \multirow{2}{*}{ Sectores } & \multicolumn{2}{|c|}{ Afios } \\
\cline { 2 - 3 } & 1971 & 1982 \\
\hline Primario & 52.2 & 40.3 \\
Secundario & 14.7 & 23.2 \\
Terciario & 33.1 & 36.5 \\
\hline Total & 100.0 & 100.0 \\
\hline
\end{tabular}

Fuente: "Explosión demográfica, empleo y trabajadores emigrantes en el Mediterráneo occidental". Congreso, Febrero 1990. Universidad de Granada, 1993.

Con una población activa de seis millones de personas en el año 1982 el paro era del $10.7 \%$; el paro urbano ha evolucionado de un $15.5 \%$ en 1986 , al $14.7 \%$ en 1987 y el $13.9 \%$ el año 1988 . No podemos olvidar que la mujer, a pesar de su progresiva incorporación al mundo del trabajo, todavía en su inmensa mayoría no es población activa; son sólo el $23.7 \%$ del total de la población activa frente al $76.3 \%$ de los hombres. Hay predominio de paro entre los jóvenes, el $46.5 \%$ del conjunto de los parados en 1988, aunque con una ligera tendencia a la disminución; ha bajado el paro juvenil del $28.7 \%$ el año 1987 al $27.5 \%$ en 1988 . De 25 a 60 años el paro ha sido del $10.6 \%$ en 1987 y el $10.1 \%$ en 1988 , que correspondía a la edad de la mayoría de los trabajadores. 
El empleo urbano se ha incrementado en lo referente al número de asalariados. En el medio rural, con un total de población de 12.727 .000 habitantes, la población activa ascendía a 5.539 .000 trabajadores, el $43.5 \%$, en su mayoría hombres; las mujeres activas rurales corresponden en su mayoría a una edad joven; hay paro rural declarado y paro rural encubierto o subempleo; el paro declarado es el 5.6\%, del cual el $8.4 \%$ corresponde a los hombres y el $15 \%$ a las mujeres. El subempleo eleva mucho la tasa con un $20.9 \%$ para los hombre y un $26.8 \%$ para las mujeres. No podemos olvidar que gran número de mujeres no aparecen en las estadísticas como población activa, pero de hecho sí lo son, con lo que elevaría la tasa de paro femenino tanto en el medio rural como en el urbano.

El empleo en Marruecos ha alcanzado una situación límite y crítica; se ha intensificado por la crisis mundial y por la política de austeridad del gobierno.

La demanda de empleo ha evolucionado de 1987 a 1992 de la forma siguiente:

Demanda de empleo en Marruecos, 1987-1992:

\begin{tabular}{|l|r|r|}
\hline \multirow{2}{*}{} & \multicolumn{2}{|c|}{ Aros } \\
\cline { 2 - 3 } & \multicolumn{1}{|c|}{1987} & \multicolumn{1}{c|}{1992} \\
\hline Demanda de empleo & 7.013 .000 & 7.975 .000 \\
Oferta de empleo & 6.171 .000 & 7.018 .000 \\
\hline Demanda de empleo no satisfecha & 842.000 & 957.000 \\
\hline
\end{tabular}

Fuente: "Explosión demográfica, empleo y trabajadores emigrantes en el Mediterráneo occidental". Congreso, Febrero 1990. Universidad de Granada, 1993.

La batalla del empleo en Marruecos se debe incluir en el conjunto de un mayor desarrollo económico y de una dinámica más potente de la vida económico-social. La descentralización, la regionalización, el desarrollo nacional integrado a la medida de los hombres y sus deseos, deben ser pautas a seguir.

Hemos visto un Marruecos con base agraria, Túnez con el inicio de un proceso de industrialización y Argelia con el desarrollo del sector servicios. Precisamente Argelia conoce una crisis estructural del sistema productivo, aumentada con la calda del precio del petróleo en 1985. 
A nivel de empleo, el fenómeno más llamativo ha sido el brutal incremento del paro sobre todo entre los jóvenes. Durante el perfodo colonial Argelia conoció un grave paro enmascarado con el subempleo; esta situación continuó en los primeros años de la independencia, en la década de los sesenta. En la década siguiente el petróleo y el gas permitieron crear ambiciosos proyectos de inversión. Hubo una gestión política del empleo sin una contrapartida salarial de acuerdo con el trabajo realizado, se creó una especie de paro en el interior de las empresas, con un empleo masivo y mal remunerado en la Administración. Todo ha redundado de forma negativa y obligó al gobierno argelino a romper con ese tipo de política económica, un socialismo a lo argelino. Ante la avalancha de jóvenes demandando empleo, la debilidad de las inversiones redujo la creación de puestos de trabajo. El empleo se agravó porque no existía un verdadero mercado de trabajo que pusiera frente a frente y ajustara la oferta de empleo y la demanda de trabajo.

En general, en Argelia se prefiere la mano de obra masculina a la femenina en el mercado de trabajo; así el $40 \%$ de los hombres ocupados son analfabetos, mientras las mujeres colocadas tienen un nivel cultural más elevado, a pesar de que en el conjunto del país la tasa de analfabetos es más elevada entre las mujeres que entre los hombres, con una proporción muy desequilibrada, el $53.8 \%$ entre las mujeres y el $31.8 \%$ entre los hombres.

El nivel cultural de las mujeres que trabajan en Argelia, año 1989, es el siguiente:

Nivel cultural de la mujer colocada en Argelia en 1989 (\%):

\begin{tabular}{|lc|}
\hline Nivel analfabeto & 22.7 \\
Nivel primario & 10.9 \\
Nivel medio & 21.5 \\
Nivel secundario & 34.0 \\
Nivel superior & 10.9 \\
\hline Total & 100.0 \\
\hline
\end{tabular}

Fuente: "Explosión demográfica, empleo y trabajadores emigrantes en el Mediterráneo occidental". Congreso, Febrero 1990. Universidad de Granada, 1993.

Relacionado con este nivel cultural de la mujer trabajadora argelina, podemos situar las diversas categorías profesionales de las mismas, que son las siguientes: 
Categorías socio-profesionales de la mujer trabajadora argelina en 1989 (\%):

\begin{tabular}{|lr|}
\hline Profesoras & 34.2 \\
Empleadas & 20.4 \\
Servicio doméstico & 11.0 \\
Ejecutivas superiores y profesiones liberales & 9.5 \\
Ejecutivas medias & 9.4 \\
Obreras & 7.5 \\
Otras categorías & 8.0 \\
\hline Total & 100.0 \\
\hline
\end{tabular}

Fuente: "Explosión demográfica, empleo y trabajadores emigrantes en el Mediterráneo occidental". Congreso, Febrero 1990. Universidad de Granada, 1993.

Sólo el 3\% de las mujeres ocupadas se dedican al trabajo agrícola; de ahí que la distribución de puestos de trabajo en el sector agrícola incrementara más el paro entre los hombres que entre las mujeres. La mujer estaba más en las labores de hogar o doméstico que como población activa en el campo, aunque trabajaran en él, causa de la debilidad de la actividad laboral en Argelia, una de las tasas de actividad más débiles del mundo, con solo el $4.7 \%$ en 1989 .

El reparto de las actividades socio-profesionales en Argelia en 1987 (\%):

\begin{tabular}{|l|c|c|}
\hline \multicolumn{1}{|c|}{ Caregorlas socio-profesionales } & \% mujeres & N.॰ mujeres \\
\hline Técnicas de la sanidad & 44.5 & 28.872 \\
Enseñanza primaria & 38.0 & 98.089 \\
Empleadas administrativas & 18.0 & 70.769 \\
Ejecutivas superiores & 17.7 & 25.484 \\
Obreras, empleadas sin cualificar & 13.7 & 54.380 \\
Empleadas de comercio y servicios & 8.9 & 10.145 \\
Obreras no agrícolas & 2.9 & 22.636 \\
\hline Total & - & 310.285 \\
\hline
\end{tabular}

Fuente: "Explosión demográfica, empleo y trabajadores emigrantes en el Mediterráneo occidental". Congreso, Febrero 1990. Universidad de Granada, 1993. 
La población activa femenina aumentó con lentitud, de 109.000 en 1966 a 571.000 en 1989, los momentos de regresión como en 1987 que descendió de 523.000 trabajadoras a 442.000 mujeres argelinas activas. El $95 \%$ de las mujeres ocupadas trabajan en medios urbanos, fundamentalmente en grandes ciudades. La tradicional costumbre paternalista musulmana se recoge en lo referente a las actividades laborales femeninas; frente al derecho al trabajo reconocido por la Constitución de 1976 para todos los ciudadanos, incluidas las mujeres, aparece el código de la familia de carácter atávico y consuetudinario, que somete a la autorización del esposo el trabajo de la mujer.

Es difícil evaluar el paro femenino ya que a muchas mujeres no se les considera población activa. En 1879 se dio una cifra de mujeres paradas, 84.700 , que suponía el $20 \%$ del total de mujeres activas, las cuales solo representan el $8.2 \%$ del conjunto de parados, evaluados en 1.033.100. Entre las mujeres paradas el $85 \%$ buscaba el primer empleo y solo el $35.8 \%$ conocían un oficio. El cambio de mentalidad de la mujer argelina en busca de trabajo, sobre todo entre las jóvenes, ha hecho aumentar la tasa de desempleo.

Para aumentar la oferta de empleo es necesario el desarrollo económico que exigen esos nuevos puestos de trabajo. En los países del Magreb se necesita un crecimiento sostenido con políticas macroeconómicas y microeconómicas, con objeto de aumentar las inversiones en capital físico y humano, dirigirlas hacia las áreas en las que más puedan utilizarse y con una mayor eficacia; es necesaria la colaboración internacional, atenuar la deuda exterior y mejorar el acceso de sus productos a los mercados de los países desarrollado. Asimismo, se impone en el campo de las instituciones interiores la democratización de los sistemas políticos con más libertad, participación, innovación y diálogo, tanto para los hombres como para las mujeres.

\section{V.-CONCLUSION.}

El desequilibrio existente en el mercado de trabajo entre oferta y demanda, muy negativo para la demanda, es uno de los retos más importantes que políticos, economistas, sociólogos, empresarios, responsables en general, tienen entre sus prioridades; pero con el pleno convencimiento que es utópico pensar en el pleno empleo. Podía incluso coexistir el desempleo rural con el desempleo encubierto en naciones con regímenes políticos autoritarios.

La caída actual de empleo a nivel mundial, muy acentuada en esta zona del Mediterráneo occidental, España, Marruecos, Argelia y Túnez, conse- 
cuencia de una grave y larga crisis económica, además de las circunstancias especiales que conocen los países de la zona, dan unas perspectivas pesimistas; con el fin de la crisis debe llegar un mayor desarrollo económico con la creación de un mayor número de puestos de trabajo y una mejor situación del mercado en cuanto a demanda y oferta de empleo.

En el caso español, la pertenencia a un bloque supranacional, la Comunidad Europea, matiza las perspectivas a que hemos hecho referencia. Mayor competencia pero con un mayor campo de actuación; será exigible cada vez más una mejor cualificación profesional con una constante actualización de los conocimientos y técnicas profesionales exigibles.

España por su situación geográfica, frontera entre la Comunidad Europea y el Norte de Africa, tiene la obligación de ser pionera en conseguir un mayor desarrollo de los países del Magreb, alentando la cooperación internacional, sobre todo, de la Comunidad Económica Europea. Lo exige la geografía y la historia de nuestro país, por el bien de todos los países de la zona implicados en esta situación y necesitados de un progresivo desarrollo humano. 